\title{
A new framework to assess industry convergence in high technology environments
}

\section{Abstract}

The process of convergence, from science and technology convergence to that of markets as well as entire industries can be witnessed in a range of different high technology environments such as IT and NanoBiotech. Although this phenomenon has been subject of analysis in an increasing number of studies, the notion of industry convergence - the final step of a full convergence process - still lacks a common definition. The missing conceptual definition of what industry convergence really is and how it can be assessed impedes both analyses and monitoring - let alone its anticipation. To address the missing conceptual definition of the final step in convergence, this paper seeks to develop a framework based on novel indicators that enable identifying and monitoring trends of industry convergence in high technology environments. Building on indicators in the domain of collaboration, a framework, which distinguishes different stages and types of industry convergence is developed. Subsequently, the newly developed framework is empirically illustrated in the area of stationary energy storage based on publicly available data. To this end, the full text database Nexis is used to conduct a search in news reports on collaborations in the domain of stationary energy storage. The study contributes to the growing body of convergence literature by providing a novel framework allowing the identification of not only industry convergence as the final step of the convergence process but also the classification of its type. Practical implications include an orientation for companies in converging environments on when and how to close the resulting technology and market competence gaps.

Keywords: collaboration; energy storage; industry convergence; process of convergence; publication analysis

\section{Introduction}

This article tackles the question of when and how the final step of an entire convergence process - industry convergence - is taking place. More specifically, the study strives to develop a framework to assess industry convergence in high technology environments with respect to its timely evolution (when, i.e. early, medium or late) as well as the convergence type (how, i.e. complementary or substitutive). A prominent example for substitutive convergence is the integration of telecommunication and computing, leading to, for example, a phasing out of the personal organizers sector (handhelds like Palm Pilot) - a sector that previously presented its own product category, though eventually becoming integrated into smart phones (Bröring, 2010). However, most cases are of complementary nature whereby two existing industry segments are complemented by a novel segment. One prominent case is the nutraceuticals sector complementing nutrition and pharmaceuticals (Curran et al 2010, Bröring and Leker, 2008).

Due to the increasing dynamics in science and technology development, industry convergence (defined as the blurring of boundaries between formerly distinct industries) is a phenomenon of growing empirical relevance. In the past decades, industry convergence gained tremendous momentum, particularly with respect to high-technology companies' strategy and innovation behavior (Curran and Leker, 2011; 
Bröring, 2010). The emergence of new technology-driven industries such as Information and Communication Technologies (ICT) partly or completely replaces existing industry structures and therewith established products, processes and business models. In such a dynamic environment, companies face increased competition including severe competence gaps, which presents a fundamental threat to their competitiveness and mere existence (Wirtz, 2001). The case of Nokia can serve as a vivid example for the necessity to identify industry convergence early, above all in high technology and fast changing business environments (Hacklin et al., 2013). In response to the formation of the ICT industry, Nokia as former world market leader in the mobile phone business did not manage to react on time to the upcoming smartphones as products emerging from convergence by adapting their strategic focus and acquiring essential new competences (Hacklin, 2008). As a result, Nokia had been acquired by Microsoft in 2013.

On a more detailed level, convergence can be described as a sequential process starting with converging scientific fields followed by a convergence of formerly distinct technologies and markets and finally leading to converging industries (Curran and Leker, 2011; Hacklin et al., 2010). As demonstrated by several studies, the phenomena of science and technology convergence is clearly defined in literature and can be identified via structured indicators based on scientific publications and patents (Curran et al., 2010; Bornkessel et al., 2014). However, the final step of industry convergence has not yet been analyzed with the same intensity as science and technology convergence, which triggers different questions: When does industry convergence happen, i.e. when does technology and/or market convergence evolve into industry convergence? Which type of industry convergence, i.e. substitutive or complementary convergence, is taking place? What are the antecedents of industry convergence that possibly allow anticipating, whether the preceding steps of science and technology convergence lead to industry convergence and thus challenge a company's competiveness? These questions demonstrate the complexity of industry convergence and highlight the need for a framework to assess industry convergence.

One reason of why literature is still missing a coherent framework to assess a "full" convergence process, reaching from science, technology to market and the entire industry, is evident in the difficulty to define what an industry itself is in the context of convergence. Without a straightforward definition of the "ex ante" state of distinct, yet not converged, industries, the convergence of different industries cannot be assessed. In order to fill the void of the missing definition of what entails an industry, Porters seminal firm perspective is used, which defines an industry as "a group of firms producing products that are close substitutes for each other" (Porter, 1980, p.5). For a detailed definition based on the Marshallian approach of industries as a collection of firms producing a homogeneous product which can be characterized by a sufficiently high cross-elasticity of demand see Rosenberg (1976, p.15). This definition is also reflected by the U.S. Standard Industrial Classification (SIC) system. Closely connected to the scholarly discussion of what constitutes an industry, is the question of what the roots of firm competitiveness in that particular industry really are. Generally speaking, in order to achieve and maintain competitiveness, companies in an industry follow industry specific "recipes" (Spender, 1989) and share similar resources and competencies (Wernerfeldt, 1984). But what happens to firm 
competitiveness if these recipes are starting to blur? This exact blurring of recipes is taking place once industries start to converge: Following the rationale that industries are composed of firms (Porter, 1980), and firms in an industry share the same recipe (Spender, 1989), one can further extend this to the competence perspective. Hence, in times of new scientific knowledge, translating into novel technologies and their applications, the underlying industry recipes based on industry specific technologies, products, regulations and industry standards starts to blur - this challenges the existing competence-base of the firms involved (Utterback and Abernathy ,1975).

The relevancy of this problem is rooted in the fact that industry convergence has a tremendous impact on the competitiveness of companies. The threat can be caused by industry convergence aggravating even more in a setting of substitutive convergence, where entire industries or industry segments are replaced by the new development and companies' core business is endangered (Bröring, 2010). To be able to react in due time to the challenges involved with industry convergence, companies need specified information on this step of the convergence process. For this purpose, the anticipation of industry convergence, mostly based on identifying technology convergence via patent analyses, serves as an early warning system (Curran et al., 2010). However, there is a substantial time lag between the appearance of technology convergence and convergence extending to the full industrial level, which nonetheless lacks any measure enabling its anticipation. Moreover, valid information on the timescale, i.e. the different stages of industry convergence, seem helpful to take action (in the effort of starting to build new competences or find collaboration partners as early as possible). Thus, there is a need for a structured approach to identify and describe the final step of industry convergence. Two very recent studies particularly stimulated this debate. Kim et al. (2015) differentiate five dynamic patterns of industry convergence based on a large-scale analysis of news articles while Geum et al. (2016) identify four types of industry convergence using 100 real world cases of converging industries. They substantially shed light on the phenomenon of industry convergence by providing evidence from a multiindustry perspective.

Against this backdrop, this article builds on and contributes to this stream of research by tackling the research question of how industry convergence can be analyzed and monitored. Hence, the study focuses on the last step of an entire convergence process, which generally starts with the confluence of distinct fields of science, technology and markets and can result in a convergence of an entire industry or its sub-segments. More specifically, the study at hand strives to develop a framework, which enables academics and practitioners to assess the final step of industry convergence in high-technology environments. The framework scrutinizes the final step (industry convergence) with respect to its timely development (when) by breaking it down into three stages as well as regarding the different types (how) of complementary or substitutive industry convergence (for the latter see Greenstein and Khanna, 1997).

The present framework is developed in a two-step process. Firstly, appropriate indicators to anticipate industry convergence are derived. These indicators are then assigned to the different stages of industry convergence and combined with the types of convergence to an analytical framework. Subsequently, the newly developed framework is empirically illustrated in the area of stationary energy storage - a 
case of an evolving new high tech sector based on the confluence of different technologies and product market application.

The present approach essentially contributes to the convergence literature in high-technology environments in three ways. Firstly, the general understanding of industry convergence as the last step of the convergence process is enhanced by presenting and defining three stages of industry convergence. Secondly, collaborations are proposed to answer the need for suitable measures to assess and anticipate industry convergence, focusing on the implications at firm-competence level. Thirdly, the novel framework to assess industry convergence allows us to identify not only the final step of convergence, stretching to the entire industry, but also to analyze the respective stages and types of industry convergence.

The remainder of this article is structured as follows. In section 2, the convergence process including its steps, drivers and types is presented. Section 3 comprises framework development, including the literature based selection of appropriate indicators. Section 4 provides an empirical proof of concept of the developed framework in the area of stationary energy storage. Implications for theory, practice and policy are discussed in section 5. A summary and an outlook on future research conclude our work in section 6 .

\section{Literature review: Steps, drivers and types of industry convergence}

The concept of convergence was firstly introduced by Rosenberg (1963) who pointed out the importance of handling technological change for improving resource allocation (Rosenberg, 1963). If new technological developments can provide value for different applications, an adoption by various industries and thus a convergence of different technology platforms is likely. Formerly independent industries characterized by a clear distance as well as by the different nature and uses of the final product are becoming technologically related (Rosenberg, 1963). The overall relevancy of convergence for different industries is reflected in a variety of research settings. ICT plays a major role (Hacklin et al., 2005; Lee et al., 2011; Schnaars and Wymbs, 2004; Lei, 2000; Athreye and Keeble, 2000), along with nanotechnology (Lo et al., 2012; Allarakhia and Walsh, 2012; Battard, 2012; Juanola-Feliu et al., 2012), nutraceuticals and functional foods (NFF) (Bornkessel et al., 2014; Bröring et al., 2006), the emerging bioeconomy (Golembiewski et al., 2015a) and neighboring disciplines of electronics such as Radio Frequency Identification (RFID) (Karvonen and Kässi, 2013; Karvonen and Kässi, 2012).

Convergence can be described as a sequential process with four steps including science, technology, market and industry convergence characterized by decreasing distances, which result in structural changes in the respective industries (see Figure 1). 


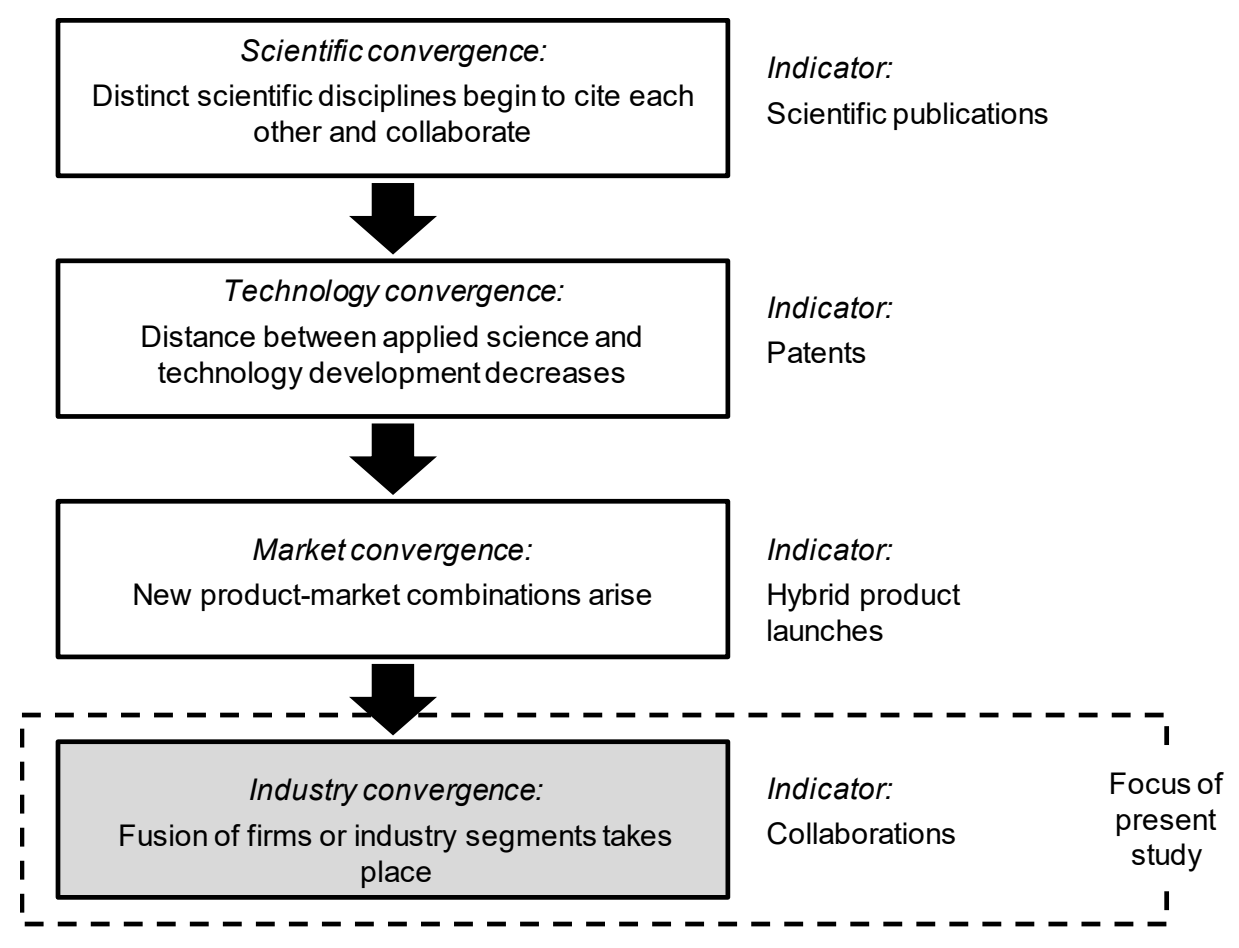

Figure 1: Idealized, sequential process of convergence (based on Curran et al., 2010).

The process starts with an increasing overlap of different scientific fields and intensified crossdisciplinary scientific research between co-existing industries and is referred to as science convergence (Jeong et al., 2016; Curran and Leker, 2011). The next step is technology convergence, which is characterized by a growing overlap of distinct technological fields and subsequently leading to new technology platforms (Lee et al., 2015; Karvonen and Kässi, 2013). Technology convergence then may lead to market convergence, characterized by new product-market combinations (Curran, 2013; Bröring, 2010, Gambardella and Torrisi, 1998). This will particularly be the case in science and technology driven industries, e.g. in the electronics or chemical industry. However, market convergence can also occur without the preliminary steps of science and technology convergence and may be triggered by changes in customer demand (Schmidt et al., 2016). Nevertheless, in the majority of empirical cases, it seems that market convergence is reinforcing the preceding technology convergence (Bröring, 2010). Depending on the impact of technology and/or market convergence has on the competence profile and competitiveness of the respective actors (i.e. firms) a full industry convergence might follow as a final step of the convergence process (Bröring and Leker, 2007; Geum et al., 2016). Industry convergence completes the overall convergence process with the emergence of a new inter-industry (segment) (Kim et al., 2015; Bröring et al., 2006). By assuming an idealized time series of events, full industry convergence will only take place when technologies and markets have converged as well, which also necessitates novel regulatory standards (Gauch and Blind, 2015). A convergence process is dynamic in nature and, therefore, can take place with varying intensity and thus with varying length of the different phases. As the steps depicted in Figure 1 are clearly overlapping and are, thus, difficult to separate, we characterized the different phases by specific indicators, e.g. co-citations between different scientific 
fields to identify science convergence, instead of time limits for each phase (Bröring, 2010; Curran and Leker, 2009; Curran and Leker, 2011).

The process of convergence is driven by developments either on the technological or the market level. This study follows the approach designed by Bröring (2010) based on Malhorta and Gupta (2001) and distinguishes between technology-driven input-side convergence and market-driven output-side convergence. Before the emergence of any technology-driven convergence movements, industries can be characterized by a certain path dependent technology development resulting in industry specific competence platforms (Bierly and Chakrabati, 2001). Caviggioli (2016) recently uncovered that technologies are more likely to converge if technological fields are closely related, cover a broad scope and stem from inter-firm collaborations. In this setting, a companies' industry-specific technological knowledge is no longer sufficient to remain competitive and hence they tend to experience a technology competence gap. Market-driven convergence, by contrast, is based on the notion that formerly independent products start substituting each other, whereby similar demand structures are developed across industry boundaries (Pennings and Puranam, 2001). In sectors of high technology, characterized by rapid technological change and short product life cycles, firms tend to vertically differentiate their products until market saturation is reached (Kim and Lee, 2009). Consequently, they begin to horizontally differentiate and integrate product features from other industries, thereby expanding their market boundaries (Kim et al., 2015). This development might be accelerated by consumers' preference for so called "one stop shopping" (the offer of a multitude of services at one location) and by the trend towards multifunctional devices which combine different utilities formerly addressed by separated, dedicated products (Hacklin et al., 2013; Pennings and Puranam, 2001). In this context, companies do not lack technological but market knowledge and are therefore confronted with a market-related competence gap (Bröring, 2010).

As a consequence of technology-driven input-side convergence and/or market-driven output-side convergence, a new industry segment as a result of a full industry convergence emerges. In more detail, if industry $A$ starts to converge with industry $B$, a new inter-industry segment $C$ emerges. The central question now is, to what extent the new segment $C$ leads to a complete phasing out of $A$ and $B$ (substitutive convergence: $A+B=C$ ) or complements the former hitherto distinct industries $A$ and $B$ (complementary convergence: $A+B=A+B+C$ ). Most cases of convergence seem to have a rather complementary nature, where firms have the opportunity to enter into the new segment, but are not forced to do so; hence their core business is not threatened (Greenstein and Khanna, 1997). An example can be seen in functional foods, where probiotic yoghurts complement the use of usual yoghurts as well as medication to promote digestion (Boehlje and Bröring, 2011). However, a complete replacement of the formerly existing segments $A$ and $B$, e.g. smartphones replacing mobile phones and mp3-players, is called substitutive convergence $(A+B=C)$. In this case, the affected companies are confronted with a completely new industry structure and lack essential capacities and competencies to cope successfully with this new situation, so that their core businesses are at least affected, if not entirely threatened (Bröring, 2010). 


\section{Framework to assess industry convergence in high-technology environments}

\subsection{Selection of indicators}

According to the process of convergence, science, technology, market, and industry convergence can be identified based on a different set of indicators (Curran, 2013). Being mainly rooted in bibliometric analyses, one advantage of science and particularly technology convergence is the availability of not only data (e.g. patent and publication databases), but also clear-cut and structured indicators and instruments for analysis. Science convergence has been identified in a small number of studies based on scientific publications, whereby co-citations showing interdisciplinary knowledge flows or coauthorships pointing towards increasing collaboration across scientific disciplines are used (Jeong et al., 2016; Vaseashta, 2014; Bornkessel et al., 2016b). The identification of technology convergence, in contrast, has been studied extensively using IPC-co-classification, co-citation and co-assignee analyses for patent documents (Lee et al., 2015; Gauch and Blind, 2015; Venugopalan and Rai, 2015; Golembiewski et al., 2015a; Curran, 2013; Niemann et al., 2013). Although there are far less studies investigating market convergence (Gambardella and Torrisi, 1998; Lee, 2007; Schmidt et al., 2016; Benner and Tripsas, 2012), launches of hybrid products emerging from convergence serve as a valuable indicator to identify converging markets (Bornkessel et al., 2016b).

On the contrary, operationalization and quantification of industry convergence still entails a variety of challenges. In a setting of industry convergence, firms are forced to develop and launch products and services with a high degree of newness. For this reason, companies may lack some of the required technology and market related resources to successfully fulfil such innovative activities, resulting in technology and market competence gaps (Grant, 1996). One of their main concerns is to close these competence gaps, preferably by finding partners with a complementary competence profile. Therefore, indicators for industry convergence explicitly have to take into account how the resulting competence gaps are closed. The main measure for companies to expand their knowledge and acquire new competences formerly related to distinct industries is cross-industrial collaboration (Enkel and Gassmann, 2010). In terms of intensity, different forms from flexible collaborations such as alliances or joint ventures to very close forms, e.g. Mergers and Acquisitions (M\&A), can be distinguished (Bornkessel et al., 2016a). For this reason, the present study draws on different forms of collaboration as suitable indicators for the final step of industry convergence.

\subsection{Development of framework}

The assignment of different indicators is based on studies by Hagedoorn and Duysters (2002) as well as Bower (2001) who investigated under which circumstances companies prefer certain forms of collaborations to get access to external innovation capabilities. In a setting of industry convergence, the affected companies take part in collaborations precisely because they lack capacities as well as competencies to operate successfully in such a setting (Bröring, 2005; Doz and Hamel, 1997; de Man and Duysters, 2005). Hagedoorn and Duysters (2002) primarily studied strategic technology alliances, $M \& A$ as well as combinations of these forms of collaboration. Their results showed that companies preferred certain forms of collaborations depending on the respective industrial and technological 
environment. Companies in high technology industries tend to use strategic technology alliances to expand their innovation capabilities because of rapid technological change and thus high levels of uncertainty force them to rely on flexible forms of collaboration (Eisenhardt and Schoonhoven, 1996). Due to the high velocity of technological knowledge in high technology environments, mutual learning processes are the focal point of these alliances (Hagedoorn, 1993). Another criterion for the selection of the form of collaboration was if the collaboration affected companies' core business or areas of less strategic relevance (Hagedoorn and Duysters, 2002). If their core business is affected, companies prefer M\&A because they provide the option to control innovation capabilities while strategic alliances create the risk of losing knowledge in an uncontrollable way (Hitt et al., 1996). Conversely, when collaborations do not affect companies' core business, strategic alliances are preferred due to higher flexibility (Dittrich et al., 2007). Since M\&A can be triggered by varying strategic reasons and thus serve very different purposes, we add to Hagedoorn and Duysters (2002) by drawing upon Bower's (2001) M\&A typology, where he explicitly mentions "industry convergence M\&A", whereby the positioning within a new industry (segment) is the primary strategic driver. In the following, the indicators are derived according to the stage and type of industry convergence.

\section{Early stage of industry convergence}

Hagedoorn and Duysters (2002) assign high technology industries with a high level of uncertainty because the technological environment is very dynamic and still changing fast. This is comparable to the early stage of industry convergence. Accordingly, companies focus on flexible collaboration types like strategic alliances and joint ventures in the early stage of industry convergence. Since technological developments have not yet been fully completed, it can be assumed that collaborations are primarily aiming at common technological Research and Development (R\&D) to close technology competence gaps (Bröring et al., 2006). This kind of collaboration type seems to be even more suitable as long as the overall convergence process is of a complementary nature. The emergence of additional industry segments relates to the environment presented by Hagedoorn and Duysters (2002), where collaborations do not affect companies' core business, so that alliances and joint ventures as looser forms of collaboration seem to be preferable in the early stage of a complementary industry convergence. However, a convergence process is of particular relevance and an eminent challenge for the affected companies if it is of a substitutive nature. The replacement of existing industry segments entails completely new industry structures and thus poses a threat to a companies' core business. In line with the reasoning of Hagedoorn and Duysters (2002), companies primarily prefer M\&A to fill their capacity and competency gaps when their core business is threatened, even in highly uncertain environments. One would expect these M\&A activities to be clearly focused on achieving synergies by tearing down existing industry boundaries and form a new inter-industry (segment), which corresponds to Bower's industry convergence M\&A. As a consequence, industry convergence M\&A are seen as indicators for a substitutive industry convergence, while in an early stage, companies may additionally consider and rely on participations in other companies to take adequate account for the high degree of uncertainty and rapid technological change. 


\section{Medium stage of industry convergence}

If industry convergence proceeds further to the medium stage, it is likely that the rate of technological change decreases, new standards are about to evolve and the overall degree of uncertainty regarding future developments slowly diminishes. The lower uncertainty concerning technological developments due to slower technological change and emerging standards allows companies to shift from mainly R\&Doriented to more market-oriented collaborations (Gauch and Blind, 2015). By extending their market and customer knowledge, companies are able to close their market competence gap. Hence, in the medium stage of complementary industry convergence strategic (market) alliances and market-oriented joint ventures seem to be the favored collaboration form. In case of a substitutive convergence, the decrease of uncertainty encourages more companies to respond to the opportunities as well as threats caused by the substitutive nature of the convergence process. Thus, companies increasingly invest into the emerging inter-industry segment, and intensify their collaboration activities. In effect, the number of industry convergence M\&A in the medium stage will presumably rise compared to the early stage.

Late stage of industry convergence:

The late and final stage represents the formation of a new inter-industry (segment) which can either complement or substitute the previous industries. New industry structures (e.g. regulations and standards) are becoming established so that uncertainty further decreases. A dominant technological design and its market application comes up, thus, a more fierce competition in the now already established new inter-industry segment arises (Suarez and Utterback, 1995). In the case of complementary convergence, this might lead to more industry convergence M\&A and reinforces novel industry structures by consolidating the new competence platform developed so far. This can also be performed by those actors who enter the newly emerging field only rather late. By contrast, in the event of a substitutive convergence, the new structure will be manifested, which implies that only very few industry convergence M\&A will still take place in the late stage. The newly formed companies will rather reshape their business units and respective business areas to position themselves in the newly emerged inter-industry segment. Table 1 provides an overview of the different stages of industry convergence including general characteristics and company behavior.

Table 1: Stages of industry convergence (based on Hagedoorn and Duysters, 2002).

\begin{tabular}{|l|l|l|l|}
\hline & \multicolumn{1}{|c|}{$\begin{array}{c}\text { Early stage of industry } \\
\text { convergence }\end{array}$} & $\begin{array}{c}\text { Medium stage of } \\
\text { industry convergence }\end{array}$ & \multicolumn{1}{c|}{$\begin{array}{c}\text { Late stage of industry } \\
\text { convergence }\end{array}$} \\
\hline $\begin{array}{l}\text { General } \\
\text { characteristics }\end{array}$ & $\begin{array}{l}\text { High level of uncertainty } \\
\text { No dominant design, rapid } \\
\text { technological change } \\
\text { Fuzzy demand structures }\end{array}$ & $\begin{array}{l}\text { Decreasing rate of } \\
\text { technological change } \\
\text { Emerging dominant design } \\
\text { and standards } \\
\text { Emerging demand } \\
\text { structures }\end{array}$ & $\begin{array}{l}\text { Formation of novel inter- } \\
\text { industry segment } \\
\text { Establishing design and } \\
\text { standards } \\
\text { Decreasing uncertainty }\end{array}$ \\
\hline $\begin{array}{l}\text { Company behavior } \\
\text { in complementary }\end{array}$ & $\begin{array}{l}\text { Companies seek } \\
\text { collaboration for R\&D }\end{array}$ & $\begin{array}{l}\text { Companies seek } \\
\text { collaboration for market }\end{array}$ & $\begin{array}{l}\text { Companies who not yet } \\
\text { entered the novel segment } \\
\text { might still join by M\&A or }\end{array}$ \\
\hline
\end{tabular}




\begin{tabular}{|l|l|l|l|}
\hline $\begin{array}{l}\text { industry } \\
\text { convergence }\end{array}$ & $\begin{array}{l}\text { related risk sharing and } \\
\text { uncertainty reduction. }\end{array}$ & $\begin{array}{l}\text { related risk sharing and } \\
\text { uncertainty reduction. }\end{array}$ & $\begin{array}{l}\text { remain in their "old" } \\
\text { industries. }\end{array}$ \\
\hline $\begin{array}{l}\text { Company behavior } \\
\text { in substitutive } \\
\text { industry } \\
\text { convergence }\end{array}$ & $\begin{array}{l}\text { Companies seek equity } \\
\text { participations to reduce } \\
\text { the threat of the upcoming } \\
\text { industry convergence on } \\
\text { their core business model } \\
\text { and seek to build new } \\
\text { R\&D competences. }\end{array}$ & $\begin{array}{l}\text { Companies seek equity } \\
\text { participations to build new } \\
\text { market related } \\
\text { competences. }\end{array}$ & $\begin{array}{l}\text { Competitive landscape } \\
\text { consolidates. }\end{array}$ \\
\hline
\end{tabular}

On this basis, an analytical framework for the investigation of industry convergence based on two dimensions is elaborated. In line with the abovementioned reasoning with respect to two types of industry convergence, the first dimension distinguishes whether convergence is supposed to take place as a complementary $(A+B=A+B+C)$ or a substitutive $(A+B=C)$ process. The second dimension relates to time, i.e. the different stage of industry convergence, namely early, medium, and late. Since the delineation between these (and, thus, over-time stages) is difficult, this classification should be viewed as a continuous rather than a stepwise classification, reflecting the dynamic nature of industry convergence and roughly dividing the final step of industry convergence into an early, medium and late stage. Finally, the indicators are classified according to this two-dimensional matrix depicted in Figure 2.

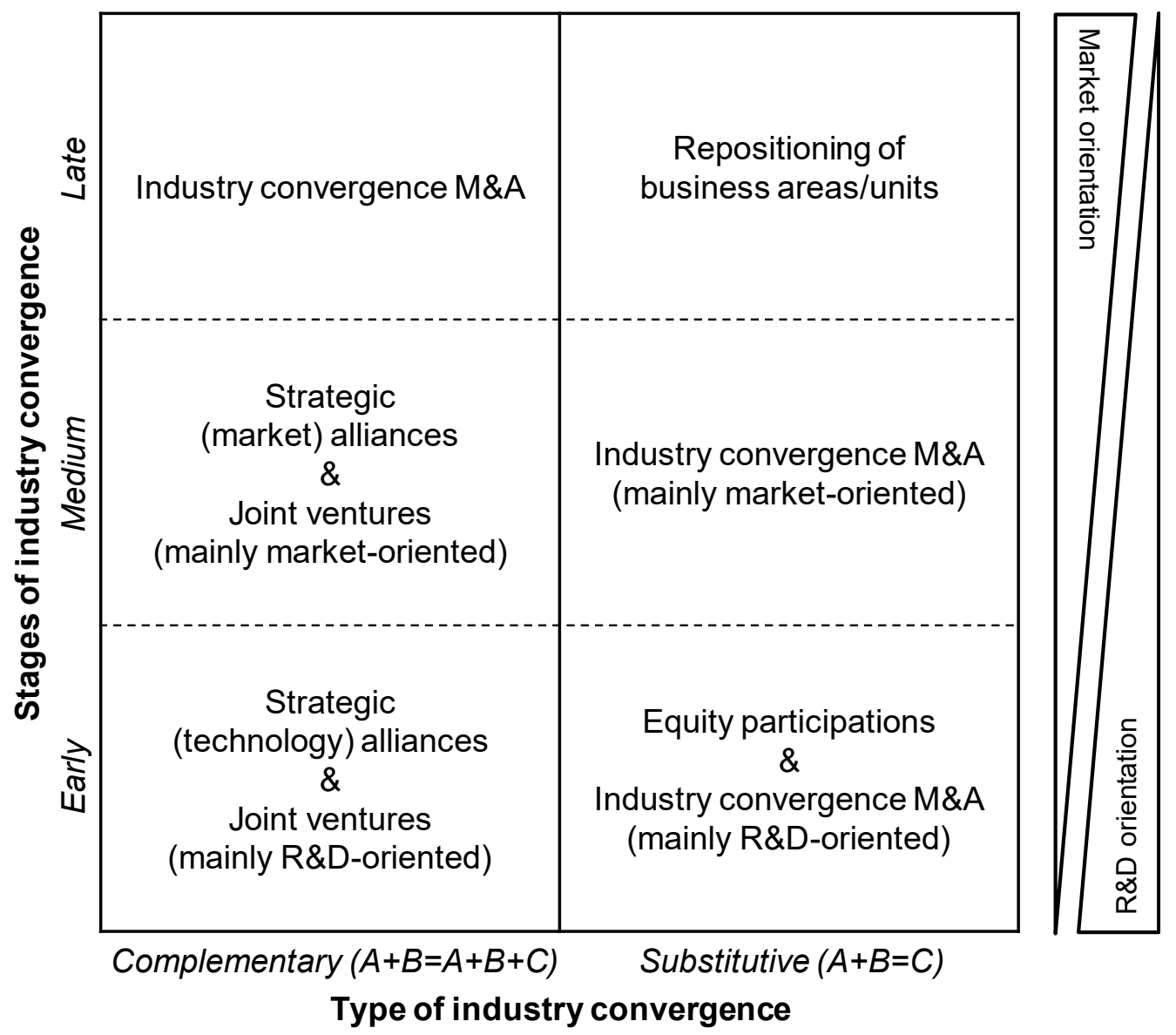

Figure 2: Framework to assess industry convergence according to the respective types and stages of industry convergence. 


\section{Illustration of the framework to assess industry convergence}

\subsection{Stationary energy storage as a field of industry convergence}

Stationary energy storage is a particularly interesting case of an emerging high technology environment to illustrate the framework. Firstly, developing new energy storage solutions is an interdisciplinary challenge, where competences from different scientific areas, technological fields and not least industries are required (Warth et al., 2013; Wagner et al., 2010; vom Stein and Sick, 2014). The stationary battery value chain reaching from materials to cell components and cells, battery systems and application is based on multiple competences. The chemical, battery, electronics and energy industry provide the pivotal competences in this context (see Figure 3) (Golembiewski et al., 2015b). Starting downstream from the application of batteries in energy applications, the energy industry is the dominating supply chain actor controlling the bottleneck to the market because of their in-depth market knowledge. Due to the complex construction of a single battery cell and the demanding interaction of the cells in a whole battery system, the electronics industry is another decisive actor in the downstream part of the value chain. Their competences range from cell level electronics to interconnecting cells to battery systems and battery systems to energy applications. Entering the upstream part of the value chain, the battery industry is mainly active in developing and assembling cell components, cells and battery systems. Moreover, the chemical industry covers the beginning of the value chain providing expertise in materials and cell components. This interdisciplinarity entails intense exchange and stronger ties between disciplines and industries, paving the way towards possible convergence movements on the level of science, technology, market and industry (Battard, 2012).

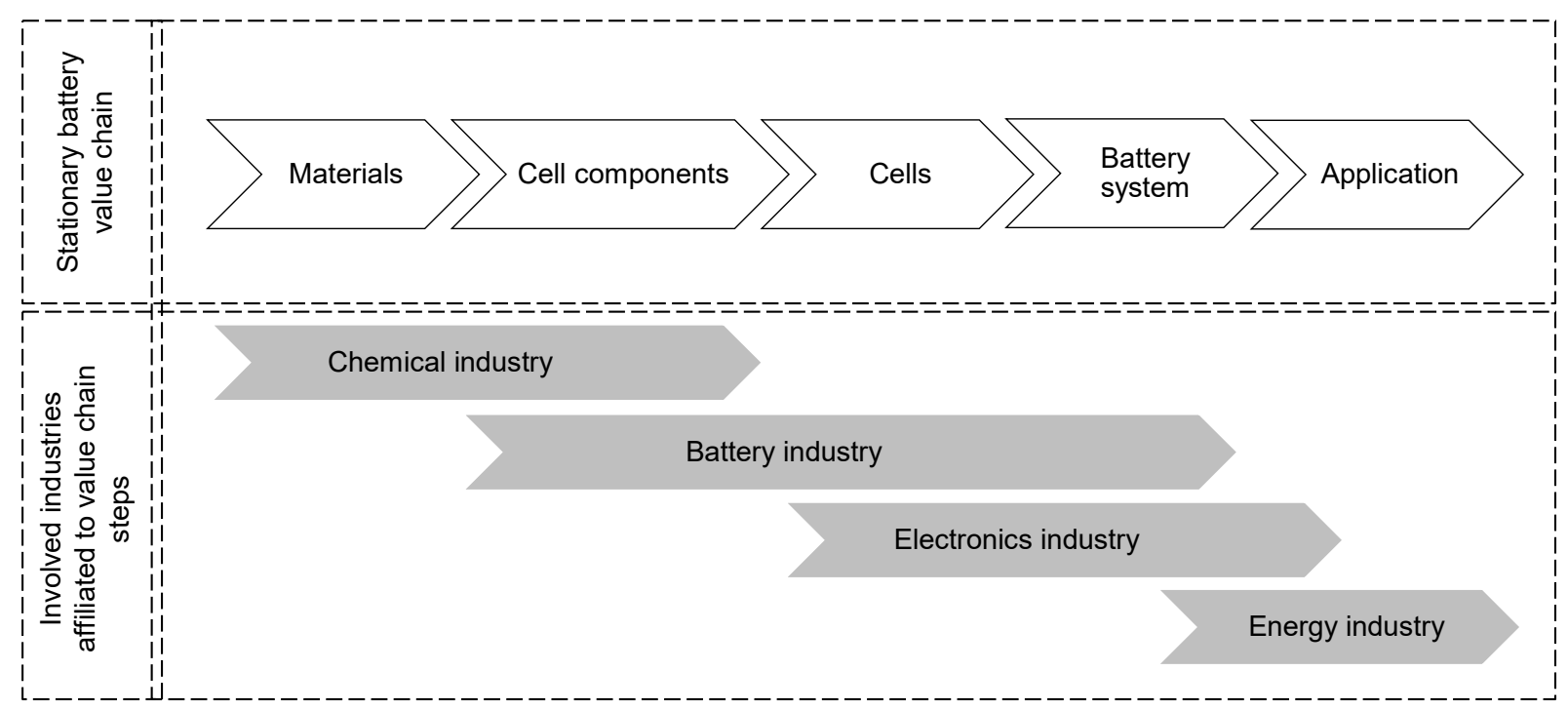

Figure 3: Industries participating in the stationary battery value chain (based on (on Delft and Leker, 2011).

Secondly, stationary energy storage is an emerging field where regulatory frameworks, involved actors from different industries, appropriate business models and competitive products and applications are still evolving (Versteeg et al., 2017). The market for conventional stationary storage applications such as fallback solutions in hospitals or in telecommunications is currently dominated by the mature leadacid technology, which has been invented more than 100 years ago. For a new field of application such 
as stabilizing power generation from renewable sources, either in private households or of industrial size, Lithium-Ion Batteries (LIB), firstly launched by Sony in 1991 and, by now, established in consumer electronics, are promising options. However, there are still serious performance and cost issues that need to be solved. In addition, noticeable market growth is expected, motivating companies to engage in energy storage activities (Ferreira et al., 2013). An example with great public appeal is currently provided by Tesla: The company builds and installs the world's largest LIB in collaboration with Neoen, a French energy utility, to guarantee electricity supply in South Australia after a statewide blackout had happened in 2016 (The Guardian, 2017). Tesla CEO Elon Musk thereby promised to deliver the battery within 100 days or he would do it for free, which impressively underlines the market dynamics in this field. In such a setting, a blurring of established industry boundaries, i.e. a convergence process, is likely to take place and thus makes the field particularly interesting for analyzing industry convergence (Linstone, 2011).

\subsection{Data and methods}

As a main source of information on collaborations, general (business) media such as newspaper articles, reports or press releases were presented (Curran, 2013). This kind of publication analysis has shown to be useful to assess developments in uncertain environments (Curran et al., 2010) and a recent study impressively proved the suitability of news articles as data source for the purpose of convergence analysis (Kim et al., 2015). The authors argue that news articles provide a broad coverage of industries, technologies and market developments, but they particularly emphasize their appropriateness as a source of information concerning "interorganizational dynamics such as alliances, joint ventures, and mergers and acquisitions." (Kim et al., 2015), p. 3).

The following steps were carried out independently by two experts (authors of the paper), to minimize the likelihood of errors by handling the process with highest possible care and applying the four eyes principle. The full text database $\mathrm{Nexis}^{\circledR}$ is used to conduct a keyword-based search in English news sources (popular press, technical press and industry reports) concerning news on collaborations on stationary energy storage systems. Before starting the publication search, appropriate keywords had to be selected. Technology-related keywords like "stationary energy storage" and "stationary battery" are combined with collaboration in general and different forms of collaboration activities like alliance, joint venture, merger or partnership in particular (Preschitschek et al., 2011). The following search string was developed: [(stationary energy storage OR stationary batter*) AND (collaboration OR joint venture OR alliance OR partnership OR merger OR acquisition)]. The search was conducted in Nexis ${ }^{\circledR}$ in October 2014 in the full text of all English news sources over the entire period available.

The keyword-based search in Nexis with the above-described search string leads to 431 results, duplicates still included. The following procedure was applied to finally identify the relevant collaborations in the field. First of all, duplicates were excluded. Subsequently, the remaining publications were analyzed concerning their relevance for collaborations in the field of stationary energy storage technologies. As a main criterion of relevance, in order to be eligible for the sample, collaborations had to have their main focus on stationary energy storage in order to be distinguishable 
from collaborations in the whole field of energy storage or collaborations focusing on mobile energy storage, e.g. for electric vehicles. Since there often is a multitude of press releases and reports on one particular collaboration, the results were bundled concerning one collaboration. Finally, 23 relevant collaborations were identified between 49 different organizations in the field of stationary energy storage in a time period from 1974 to 2014.

In the next step, structured information on the relevant collaborations and collaboration partners was collected, whereby we identified types of collaboration, year of start, industry or research partner, intraindustry or cross industrial collaboration, market or R\&D focus as well as industry affiliation of the companies involved. To assess industry affiliation, industry information provided by Hoovers with more than 85 million companies within 1000 industry segments was used. The website provides detailed information on each of the companies in our sample with a focus on industry affiliation including SIC and North American Industry Classification System (NAICS) codes. Hoovers thereby provides a higher level of abstraction for industry affiliations, but at the same time specifies the respective fine-grained SIC and NAICS codes for each industry. This information allowed to align the industry affiliation of the involved organizations with the industries identified within the stationary battery value chain provided in Figure 3. The industry affiliation of the respective collaboration partners is sometimes ambiguous, e.g. concerning large multinational conglomerates. It was therefore decided to assign every company to one, i.e. the most relevant industry in terms of its activities, to ensure a maximum level of comparability. Based on this information, an overview of the main players and developments in the industries is provided. The resulting collaborations are subsequently assigned to the industry convergence framework.

\subsection{Assessment of industry convergence in stationary energy storage}

Most of the 23 collaborations (20, representing $87 \%$ of the overall sample) are dyadic, while three collaborations consist of three partners. Overall, 46 different companies and three research institutions take part in these 23 collaborations, whereby only three companies in the present sample participate in more than one collaboration. When looking at the timeline regarding the start of the collaborations, it becomes apparent that only few activities have been undertaken before 2007 as we could only identify one collaboration in 1976, 1994 and 2000, respectively (Figure 4). These collaborations focused on the development of rather mature technologies such as zinc-chlorine batteries, the production of lead-acid industrial batteries in China and demonstration as well as further development of vanadium-redox batteries for the South African market. 


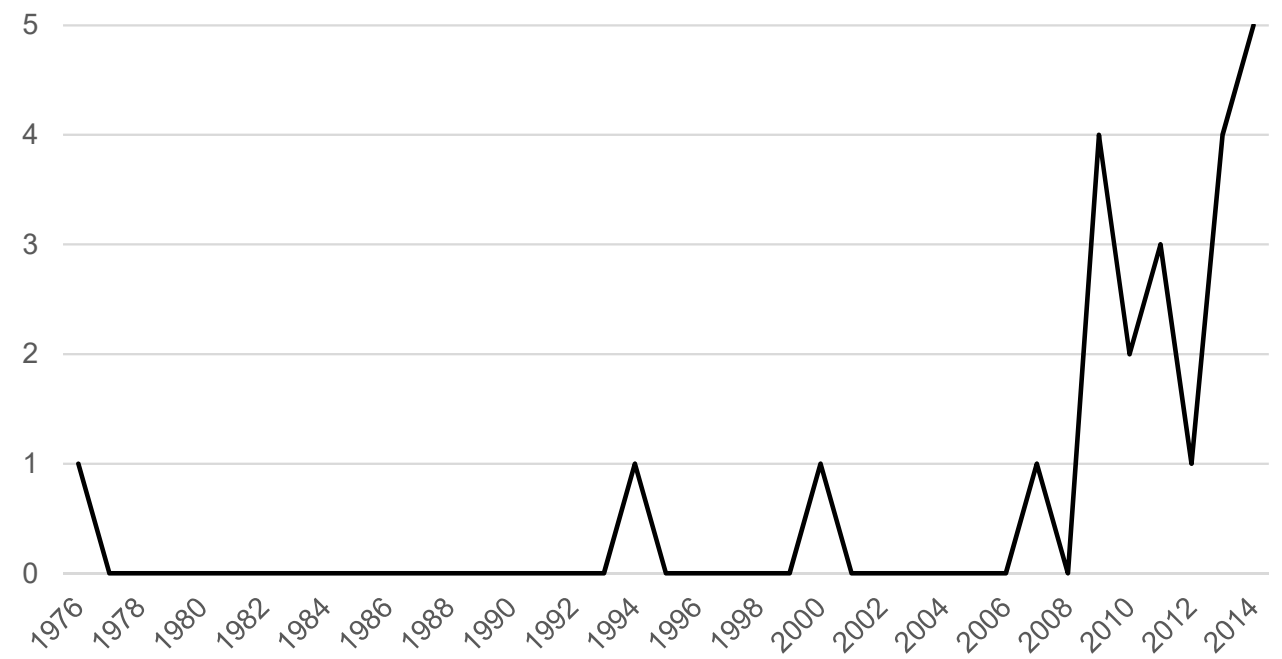

Figure 4: Timeline of agreements on stationary energy storage collaborations.

For the purpose of analyzing industry convergence along the lines of the proposed framework, the type of collaboration as well as the collaboration intensity associated to every type is of particular interest. In the present sample, seven different types of collaborations are identified. Sorted by descending collaboration intensity, these are mergers, joint ventures, strategic alliances or partnerships, agreements, projects, Memorandum of Understanding $(\mathrm{MoU})$ and licensing. Although licensing involves signing a contract, $\mathrm{MoU}$ is considered as an indicator for a higher collaboration intensity due to its more comprehensive nature. While licensing is often very specific and refers to a single event, a MoU forms the basis for further, more intense collaboration. The largest part with about $25 \%$ of the respective collaborations can be assigned to agreements, which show collaboration intensity on a medium level. Noticeable are the six different kinds of agreements, from more R\&D-oriented collaborations such as research and joint development agreements to more market-oriented collaborations such as manufacturing service or strategic supply agreements. Less collaboration intensity can be observed in three projects, two MoU and one case of licensing while a higher degree of intensity is reflected in five strategic alliances or partnerships, four joint ventures and, finally, two mergers.

Apart from collaboration intensity, the industries to which the respective collaboration partners can be assigned to, play a designated role in the analysis of industry convergence. More than one third of the companies involved in collaborations focusing on stationary energy storage belong to the battery industry. Further relevant industries are the energy and electronics industry with about $17 \%$, respectively. Only $7 \%$ of the companies belong to the chemical industry; research institutions hold an equal share. Less than $5 \%$ can be assigned to IT, manufacturing, automotive, licensing, telecommunication and trading, respectively.

Only three out of 23 collaborations (or 13\%) are intra-industry collaborations and all these collaborations are formed by partners from the battery industry. The remaining 20 collaborations are cross industrial collaborations with battery and electronics, battery and energy as well as energy and electronics as dominant industry combinations (see Figure 5). Further combinations, e.g. between battery and IT or energy and licensing, are represented by only one collaboration each. On the one hand, these results 
confirm the dominance of the battery, energy and electronics industry in the field of stationary energy storage technologies. In sum, more than two thirds of the companies belong to these dominating industries and thus seem to hold the most relevant competences in this field. On the other hand, the collaboration landscape still seems to be quite scattered with ten industries (research organizations not included) involved in very different kinds of collaborations. Moreover, the striking dominance of cross industrial collaborations underlines the assumption that competences from different industries are needed for stationary energy storage development. In this context, the intense ongoing collaborations between battery, electronics and energy industry show that companies are still acquiring, transferring and combining new knowledge from cross industrial partners to establish new stationary energy storage solutions.

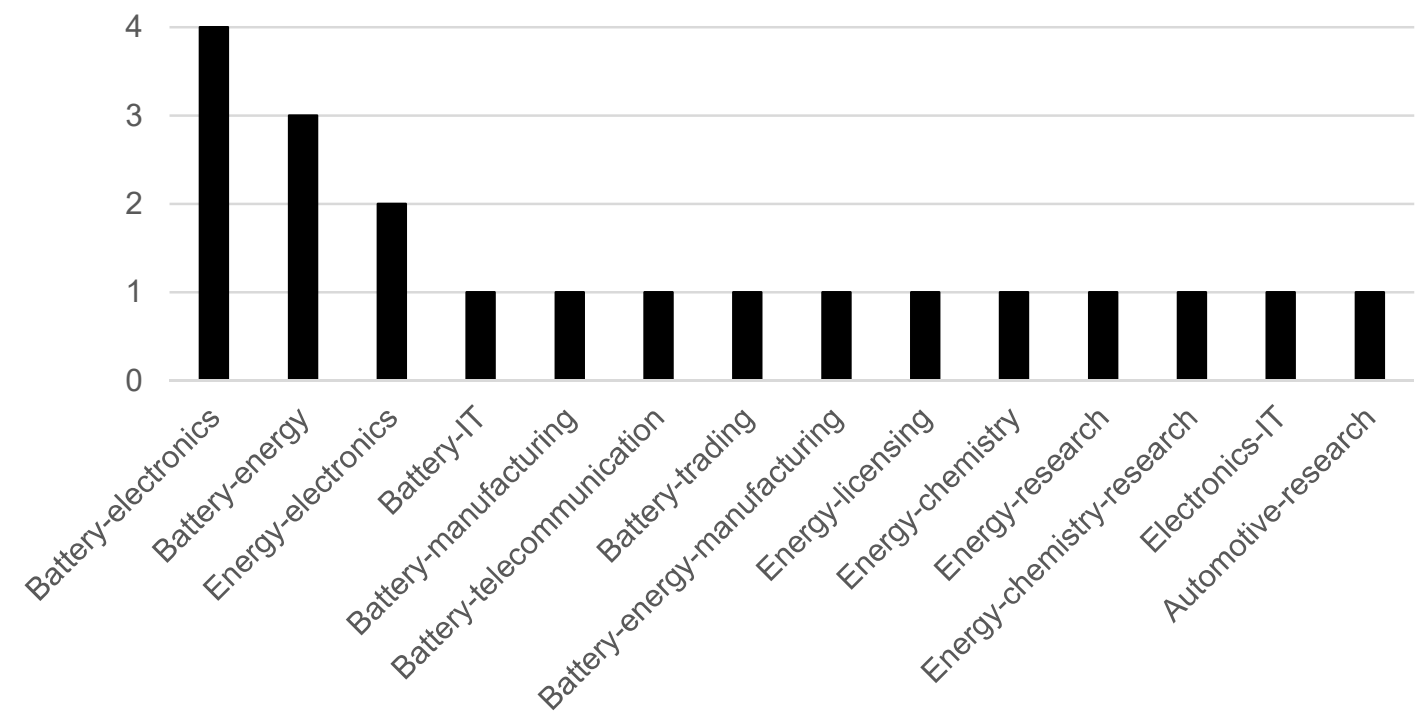

Figure 5: Cross sectoral collaborations in the field of stationary energy storage.

Another pivotal aspect that has to be taken into account regarding the analysis of industry convergence is the differentiation between $R \& D$ and market orientation of the respective collaborations. By engaging in R\&D oriented collaborations, firms intend to close technology competence gaps in an earlier stage of industry convergence. Market competence gaps, in contrast, are closed based on market oriented collaborations with partners providing e.g. customer knowledge or market access. In the present sample, nearly equal shares of the two collaboration orientations are identified, namely 11 R\&D-oriented and 12 market-oriented collaborations. Among the 11 R\&D-oriented collaborations, two joint ventures, three strategic alliances or partnerships, four agreements, and one collaboration based on a MoU and licensing are found. One interesting example is the research agreement between the Massachusetts Institute of Technology (MIT) and Total, a French energy company. Under the MIT Energy Initiative, the two collaboration partners agreed on developing low-cost and long-life stationary batteries to store solar power. Total, formerly focused on oil and gas, became a major player in solar energy, where stationary storage is a mandatory requirement for exhaustive use. Another worthwhile endeavor is carried out by American LIB producer EnerDel and the real-estate branch of Itochu, a Japanese trading corporation. The partnership aims at developing and producing advanced battery systems for a residential smart grid energy storage project in Tokyo. 
In terms of market-oriented collaborations, the sample includes two mergers, two joint ventures, two strategic alliances or partnerships, two agreements, three projects and one MoU. A German joint venture named "Energy Storage North" between Robert Bosch $\mathrm{GmbH}$ and wind park operator BWP builds and operates a large battery for the wind park operated by BWP in Northern Germany. In comparison with the R\&D-oriented project between MIT and Total to close technology competence gaps in battery development, this collaboration clearly focuses on closing market competence gaps by "validat[ing] the technical and financial benefits of the battery and provide valuable insights for new commercial projects" (Robert Bosch $\mathrm{GmbH}$, 2013). In addition, the two mergers can be categorized as industry convergence M\&A. The reasoning behind the collaboration between Midtronics, offering technologies for battery management, and Lynai Data Incorporated (LDI), offering battery data management software, was to expand product offerings for the changing market requirements in the stationary battery field. A similar motivation triggered the collaboration between EnerSys, manufacturer of industrial batteries, and Oerlikon Batteries, namely to extend market leadership in industrial energy storage and establish a new product development center.

From a chronological point of view, it can be stated that R\&D-oriented collaborations in stationary energy storage reach a peak in $\mathbf{2 0 0 9}$ and afterwards fluctuate on a lower level and finally not any R\&D-oriented collaboration was found for 2014 (see Figure 6). The first R\&D-oriented collaboration was started in 1976, focusing on the development of zinc-chlorine batteries to provide higher performance and lower costs than conventional lead-acid batteries. With the advent of LIB in 1991, zinc-chlorine technology has not been retained in full for stationary storage applications. The subsequent collaborations between 2007 and 2012 concentrated on LIB, whereby the later ones developed new materials for next generation LIB with increased performance. The latest collaborations in 2013, in contrast, aim at developing alternative technologies such as vanadium redox flow batteries to further increase performance and decrease costs.

Market-oriented collaborations, in contrast, grow in recent years with up to five collaborations in 2014, while the two mergers taking place in 2009 and 2010 already signalize the upcoming market-orientation in stationary energy storage. The first joint venture in 1994 aimed at the production of lead-acid industrial batteries in China for telecommunication applications. Along with the fact that there is no R\&D-oriented collaboration on lead-acid batteries, this reflects their status as a mature technology for established industrial applications. Due to the limited profitability of stationary storage options, the following collaborations mainly cover demonstration sites and pilot projects to figure out commercialization opportunities for stationary storage concerning renewable energies such as wind and solar parks, further grid stability needs as well as private housing. Thereby, the collaborations focus mostly on LIB, while two collaborations are on vanadium redox flow batteries. This corresponds to the technological priorities of the R\&D-oriented collaborations, trying to scale-up and show application opportunities for LIB and, to some extent, vanadium redox flow batteries.

Thus, the focus of the examined collaborations in the field of stationary energy storage is currently shifting from mainly R\&D towards market orientation. This development indicates that companies already took action to close their technology competence gaps and are now predominantly concerned 
with closing their market competence gap. As the sample does not claim to be complete and the amount of collaborations is subject to fluctuations, these observations may be taken as a first indicator instead of being hard evidence and have to be set in the wider context of industry convergence analysis.

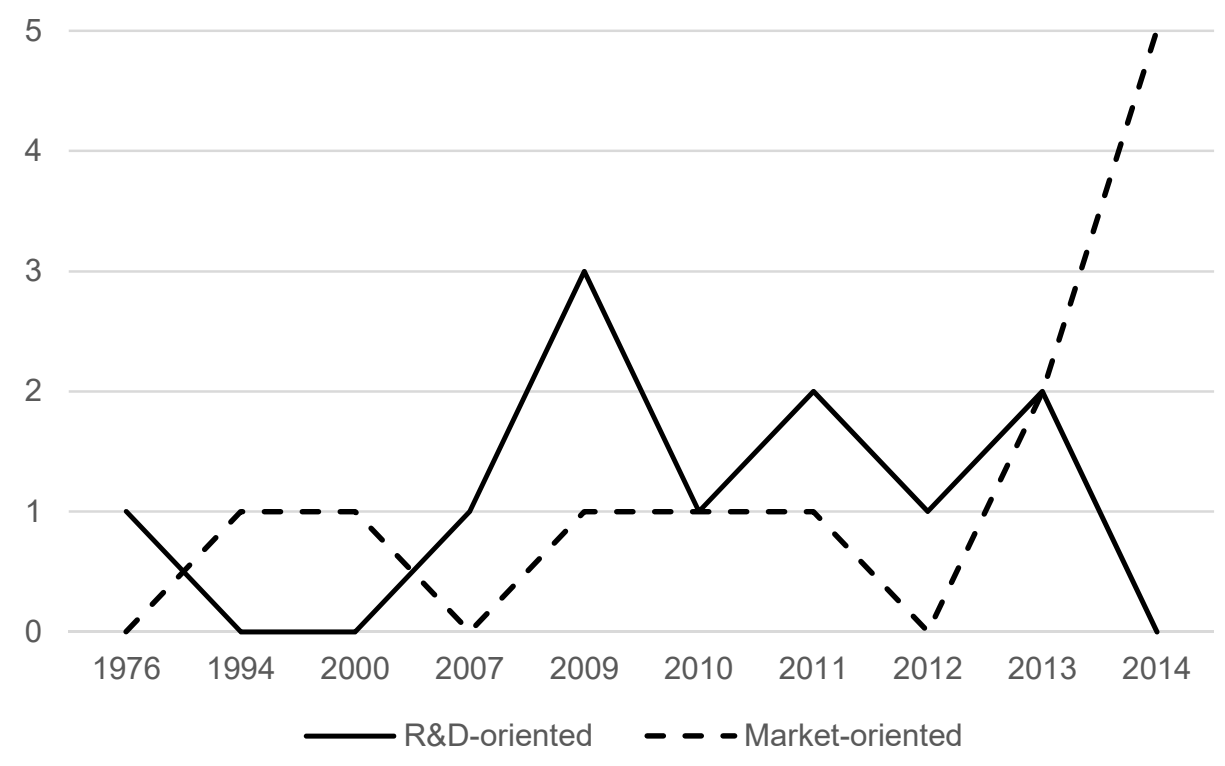

Figure 6: Development over time of mainly R\&D-oriented vs. mainly market-oriented collaborations.

An overview of collaborations including industry affiliation and type of collaboration according to the respective battery value chain step is presented in Figure 7. We are well aware that the figure is less suitable to provide detailed insight into every single collaboration and its particular characteristics, but should rather illustrate the collaboration network with numerous participants from various industries collaborating on different levels of intensity. In addition, the figure illustrates that the majority of industries involved in the convergence process can be located in the upstream part of the value chain. This strengthens the aforementioned finding that market-oriented collaborations are dominating in this area and that industry convergence in stationary energy storage is mainly market-driven. 


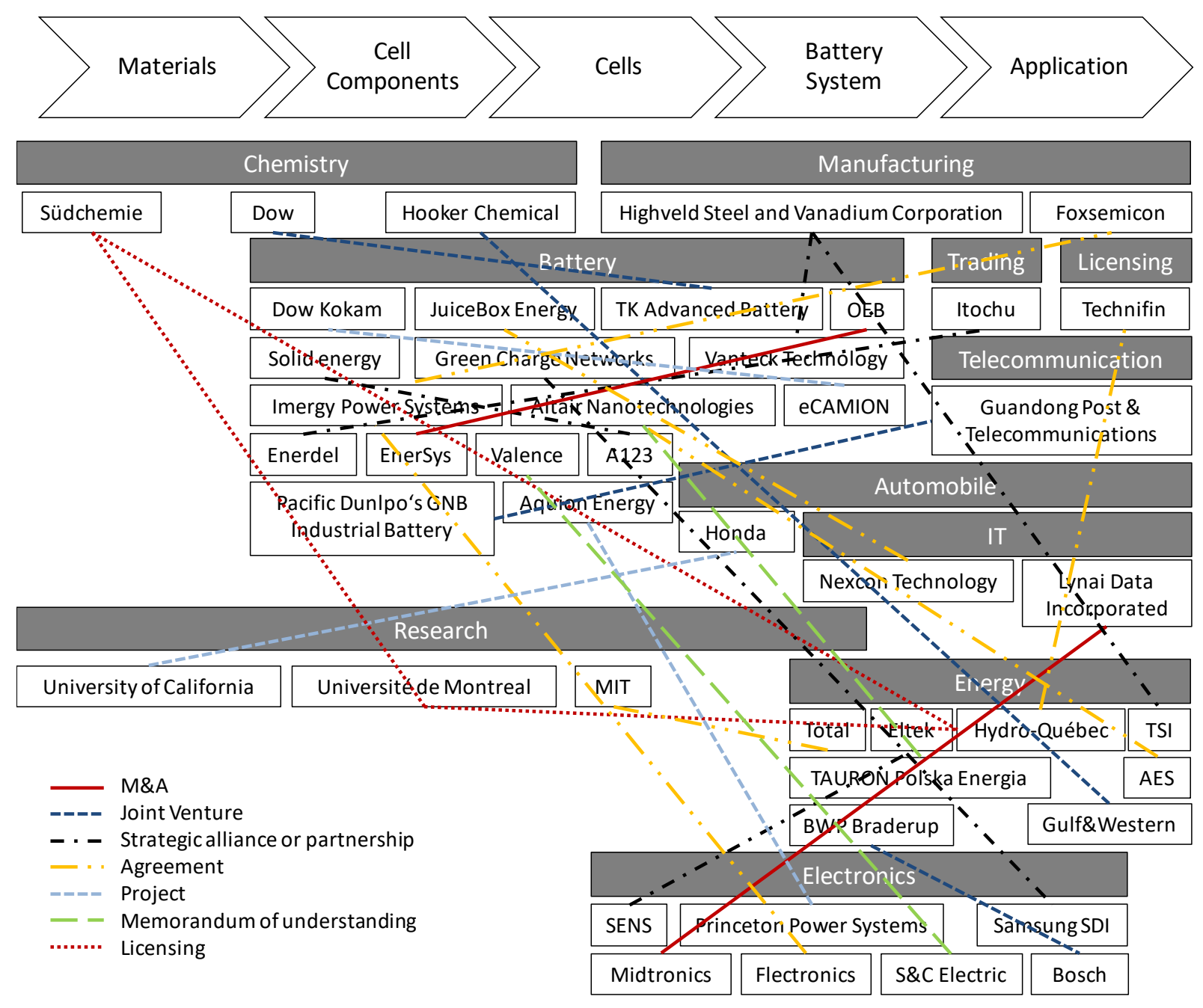

Figure 7: Collaborations in the field of stationary energy storage.

The identified collaborations are then classified according to the analytical framework presented (see Figure 8). The wide variety of agreements, strategic alliances and joint ventures points towards a complementary industry convergence in the field of stationary energy storage. This is supported by the observation that most of the companies active in the field do not seem to abandon their core business, but rather expand business opportunities within this area of convergence. A total of 11 collaborations, which are mainly R\&D-oriented, can be assigned to the early stage of industry convergence, whereas ten collaborations belong to the medium stage since they show more market orientation. Two collaborations, both mergers, can even be assigned to the late stage of industry convergence. The chronological analysis confirms that the different stages of industry convergence follow a sequential path, but following the theoretical reasoning, the stages also show a certain overlap. For this reason, activities, i.e. collaborations, in combination with their timely development turn out to be appropriate indicators. It can thus be concluded that industry convergence in the area of stationary energy storage is currently located in the medium stage, while the fact that two mergers have already been completed points towards the imminent formation of a new sub segment of the involved industries. 


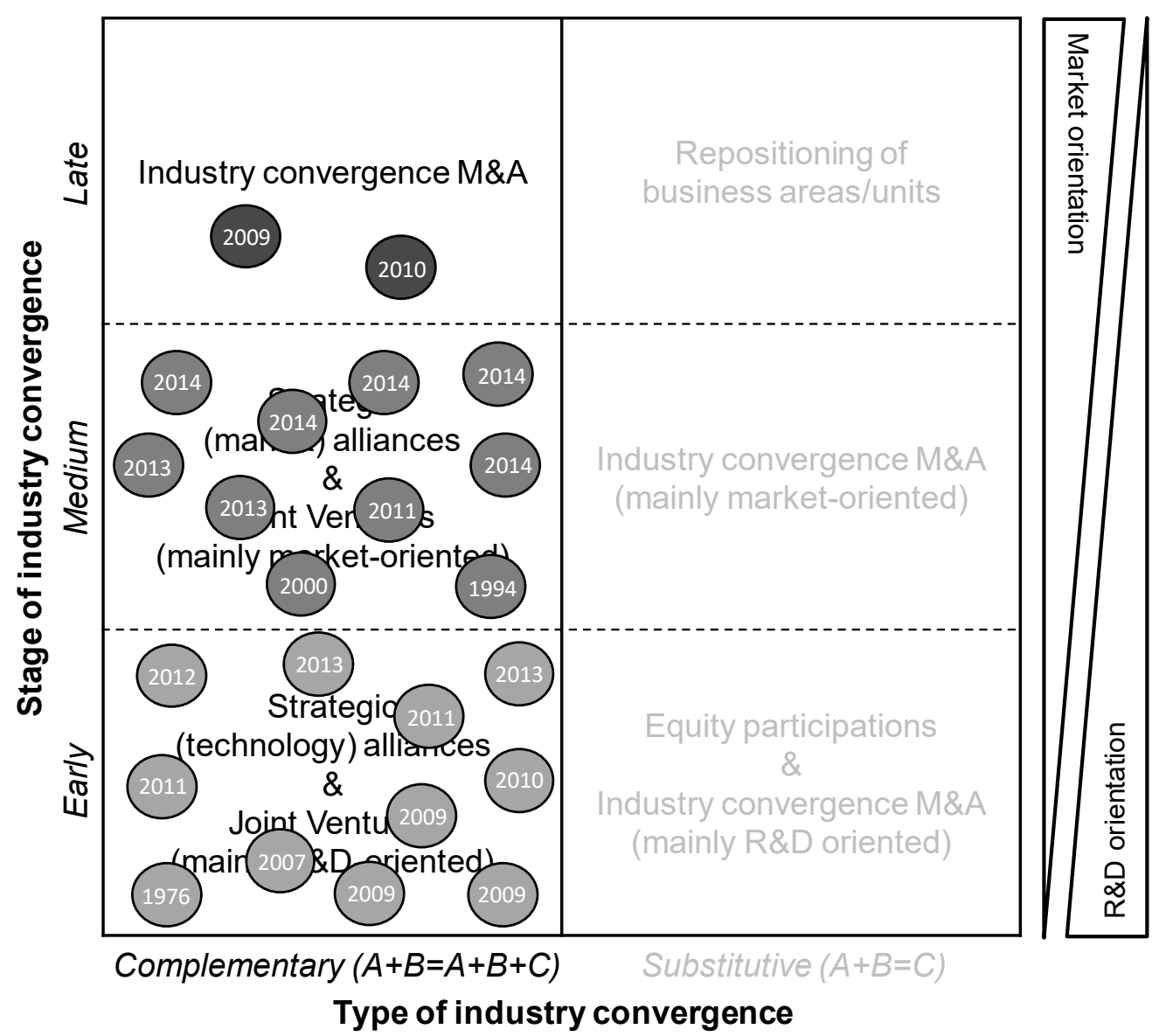

Figure 8: Industry convergence in the field of stationary energy storage.

\section{Discussion}

\subsection{Implications to theory}

Development and empirical illustration of the framework widen our theoretical understanding of industry convergence as the final step of an entire convergence process. Following the differentiation of five dynamic patterns of industry convergence of Kim et al. (2015) and the identification of four types of industry convergence of Geum et al. (2016), this paper provides a definition of industry convergence, which clarifies the notion of an industry as the basis for the definition. Furthermore, a common conceptual definition of industry convergence, particularly a delineation to market convergence, which was previously missing in the emerging field of convergence research, is added. The current paper highlights that convergence on industry level takes place when firms start to finally close their technology and market competence gaps.

Secondly, the three stages of industry convergence developed in this paper - early, medium and late - further enhance conceptual clarity of industry convergence in high technology environments. Based on this temporal classification of industry convergence, an opportunity to detect the actual step of industry convergence at a very early point in time is presented. This timeframe also contributes to the literature on the speed of industry convergence, such as the work by Lee et al. (2016), which investigates 
the comparative speed of industry convergence in high-technology industries and explores the correlation between the industry convergence potential and the convergence growth rate.

Thirdly, convergence researchers urgently called for a suitable measure to assess and anticipate industry convergence (see e.g. Kim et al., 2018), which, up to now, mainly relied on technology convergence as an early indicator for a possibly upcoming industry convergence. Based on the theoretical argument that companies aim at closing their competence gaps in the final step of the convergence process, the present paper proposes collaborations as indicators to identify and anticipate industry convergence. It follows on from the research by Caviggioli (2016), which proposes that interfirm collaborations foster convergence. The assignment of different forms of collaboration to the respective stages and types of industry convergence also connects convergence research to open innovation and knowledge transfer. As suggested by Bröring (2010), the wider the technology and market competence gaps, the more imperative is an open innovation strategy to close these gaps. The framework developed in this study provides valuable guidance on how and when to implement an open innovation strategy, i.e. which forms of collaboration can be used best in which stage and type of industry convergence. In a similar vein, Dingler and Enkel (2016) argue that knowledge transfer across industry boundaries - a prerequisite to close competence gaps in converging environments - is particularly challenging. The authors introduce socialization effects such as a common language, norms of communication or a distinct identity for the involved partners as a possible solution. In this context, the presented framework can help to assess what kind of knowledge to transfer using which form of collaboration, depending on the stage and type of industry convergence.

\subsection{Implications to practice}

The framework provides the affected companies with an indication when the respective industry boundaries start blurring and competitors combine their knowledge and competences in order to develop new business opportunities. The assessment of industry convergence helps in making early strategic decisions on when and how to close technology and market competence gaps. On the one hand, the early and continuous observation of the convergence process means finding new collaboration partners early; on the other, realizing the presence of new competitors, who were previously active in different arenas. Furthermore, the framework helps companies to enter the competition for collaboration partners across industry borders early. Therefore, the distinction between technology and market competence gaps and the corresponding forms of collaborations can help firms to better position themselves in converging environments by identifying the applicable gap as well as suitable measures to close this gap.

The framework can also be used to monitor developments within a firms own field of activity, i.e. competitive analysis, in order to track strategic collaborations. The present framework not only enables managers to classify the stage and type of an emerging industry convergence process, but also provides guidance with respect to forming collaborations. Hence, the approach raises awareness for a timely managerial action by detailing the general characteristics of industry convergence and defining new measures for monitoring it. 


\subsection{Implications to policy}

The classification of industry convergence allows policy makers to understand the phenomenon of industry convergence in more detail and hence helps to address its challenges. Firstly, if industry convergence takes place, it has to be decided how to proceed with industry regulations. Since industries face different regulatory measures, it has to be discussed which measures will be used, or whether the measures will be combined, resulting in a new set of regulations specific to the newly formed industry segment.

Secondly, active policy may take place, where convergence is fostered through deregulation or slowed down through intensified regulation. Although we have not yet tested it, the monitoring capacity of our framework might serve as a tool to elucidate concentration levels in certain industries. Thus, it is of high relevance for competition law and antitrust. This seems to be especially relevant for substitutive cases of industry convergence, where the fusion of two distant industries implies new market boundaries, which might result in different levels of concentration.

\section{Conclusion}

In response to the need to analyze convergence taking part on an industry level as the last step of the sequential convergence process, this study presents a literature-based analytical framework to assess industry convergence in high technology environments. Drawing on the notion that in a setting of industry convergence, firms are forced to close technology as well as market competence gaps by collaborating with complementary partners, different forms of collaboration are presented as suitable indicators for industry convergence. By assigning the different forms of collaboration to the respective stages and types of industry convergence, a framework is developed, which allows a detailed analysis of the final step of industry convergence. The framework is illustrated using the case of stationary energy storage. The empirical illustration confirms the suitability of the approach and reveals a complementary industry convergence in the medium stage in the area of stationary energy storage.

Notwithstanding the theoretical and practical implications of the findings, the present study faces several limitations. Although stationary energy storage has been selected as a suitable and particularly interesting case for high technology environments, we are well aware that the illustration of one case of industry convergence only allows limited generalizability. Although the present study provides a good starting point to classify industry convergence, further research in this area is needed to develop more detailed frameworks or tools to allow for assessing the antecedents of industry convergence. Major points in this context will be the illustration of the present framework in case of substitutive convergence and the adaptation of the framework to low tech environments or service industries. An interesting aspect could be the integration of regulatory convergence into the framework, i.e. the development of new standards as a prerequisite for industry convergence. From a methodological point of view, a keyword-based search always implicates some shortcomings due to a certain degree of arbitrariness in selecting keywords. As a response to this challenge, the study relies on an established approach in a very similar research setting (presented in Preschitschek et al., 2011). Furthermore, the news 
documents had to be manually scanned to identify the relevant information on collaborations. Here, the likelihood of errors was minimized by handling the process with highest possible care and applying the four eyes principle, so that two experts in this field independently searched for the relevant collaborations. We also relied on a single database to identify the respective collaborations. Therefore, it would be worthwhile to use additional databases and sources to gather more data and identify different forms of collaborations. In this context, approaches based on big data analyses may prove valuable.

\section{References}

Allarakhia, M., Walsh, S., 2012. Analyzing and organizing nanotechnology development: Application of the institutional analysis development framework to nanotechnology consortia. Technovation 32, 216226.

Athreye, S., Keeble, D., 2000. Technological convergence, globalisation and ownership in the UK computer industry. Technovation 20, 227-245.

Battard, N., 2012. Convergence and multidisciplinarity in nanotechnology: Laboratories as technological hubs. Technovation 32, 234-244.

Benner, M.J., Tripsas, M., 2012. The influence of prior industry affiliation on framing in nascent industries: The evolution of digital cameras. Strategic Management Journal 33, 277-302.

Bierly, P.E., Chakrabarti, A., 2001. Dynamic knowledge strategies and industry fusion. International Journal of Manufacturing Technology and Management 3, 31-48.

Boehlje, M., Bröring, S., 2011. The increasing multifunctionality of agricultural raw materials: Three dilemmas for innovation and adoption. International Food \& Agribusiness Management Review 14, 116.

Bornkessel, S., Bröring, S., Omta, S.W.F., 2014. Analysing indicators of industry convergence in four probiotics innovation value chains. Journal of Chain and Network Studies .

Bornkessel, S., Bröring, S., Omta, S.W.F., 2016a. Cross-industry collaborations in the convergence area of functional foods. International Food and Agribusiness Management Review 19, 75-98.

Bornkessel, S., Bröring, S., Omta, S.W.F., 2016b. Crossing industrial boundaries at the pharmanutrition interface in probiotics: A life cycle perspective. PharmaNutrition 4, 29-37.

Bower, J.L., 2001. Not all M\&As are alike - and that matters. Harvard Business Review, March 2001, 92-101.

Bröring, S., Cloutier, M.L., Leker, J., 2006. The front end of innovation in an era of industry convergence: Evidence from nutraceuticals and functional foods. R\&D Management 36, 487-498.

Bröring, S., 2010. Developing innovation strategies for convergence - Is 'open innovation' imperative? International Journal of Technology Management 49, 272-294.

Bröring, S., 2005. The front end of innovation in converging industries. The case of nutraceuticals and functional foods. DUV, Wiesbaden.

Bröring, S., Leker, J., 2007. Industry convergence and Its implications for the front end of innovation: A problem of absorptive capacity. Creativity and Innovation Management 16, 165-175. 
Caviggioli, F., 2016. Technology fusion: Identification and analysis of the drivers of technology convergence using patent data. Technovation 55-56, 22-32.

Curran, C., Leker, J., 2011. Patent indicators for monitoring convergence - Examples from NFF and ICT. Technological Forecasting and Social Change 78, 256-273.

Curran, C., 2013. The anticipation of converging industries. A concept applied to nutraceuticals and functional foods. Springer, Heidelberg.

Curran, C., Bröring, S., Leker, J., 2010. Anticipating converging industries using publicly available data. Technological Forecasting \& Social Change 77, 385-395.

Curran, C., Leker, J., 2009. Employing STN anavist to forecast converging industries. International Journal of Innovation Management 13, 637-664.

de Man, A., Duysters, G., 2005. Collaboration and innovation: A review of the effects of mergers, acquisitions and alliances on innovation. Technovation 25, 1377-1387.

Dingler A.; Enkel E., 2016. Socialization and innovation: Insights from collaboration across industry boundaries. Technological Forecasting \& Social Change, 109, 50-60.

Dittrich, K., Duysters, G., de Man, A., 2007. Strategic repositioning by means of alliance networks: The case of IBM. Research Policy 36, 1496-1511.

Doz, Y., Hamel, G., 1997. The use of alliances in implementing technology strategies, in Tushman, M.L., Anderson, P. (Eds.), Managing Strategic Innovation and Change. Oxford University Press, Oxford, pp. 556-581.

Eisenhardt, K.M., Schoonhoven, C.B., 1996. Resource-based view of strategic alliance formation: Strategic and social effects in entrepreneurial firms. Organization Science 7, 136-150.

Enkel, E., Gassmann, O., 2010. Creative imitation: Exploring the case of cross-industry innovation. R\&D Management 40, 256-270.

Ferreira, H.L., Garde, R., Fulli, G., Kling, W., Lopes, J.P., 2013. Characterisation of electrical energy storage technologies. Energy 53, 288-298.

Gambardella, A., Torrisi, S., 1998. Does technological convergence imply convergence in markets? Evidence from the electronics industry. Research Policy 27, 445-463.

Gauch, S., Blind, K., 2015. Technological convergence and the absorptive capacity of standardisation. Technological Forecasting and Social Change 91, 236-249.

Geum, Y., Kim, M., Lee, S., 2016. How industrial convergence happens: A taxonomical approach based on empirical evidences. Technological Forecasting and Social Change 107, 112-120.

Golembiewski, B., Sick, N., Bröring, S., 2015a. Patterns of convergence within the emerging bioeconomy - The case of the agricultural and energy sector. International Journal of Innovation and Technology Management 12, 1550012-1-1550012-22.

Golembiewski, B., vom Stein, N., Sick, N., Wiemhöfer, H., 2015b. Identifying trends in battery technologies with regard to electric mobility: Evidence from patenting activities along and across the battery value chain. Journal of Cleaner Production 87, 800-810.

Grant, R.M., 1996. Toward a knowledge-based theory of the firm. Strategic Management Journal 17, 109-122. 
Greenstein, S., Khanna, T., 1997. What does industry convergence mean?, in Yoffie, D. (Ed.), Competing in the Age of Digital Convergence. Harvard University Press, Boston, pp. 201-226.

Hacklin, F., Battistini, B., Krogh, G.v., 2013. Strategic choices in converging industries. MIT Sloan Management Review 55, 65-73.

Hacklin, F., Marxt, C., Fahrni, F., 2010. An evolutionary perspective on convergence: inducing a stage model of inter-industry innovation. International Journal of Technology Management 49, 220-249.

Hacklin, F., Raurich, V., Marxt, C., 2005. Implications of technological convergence on innovation trajectories: The case of ICT industry. International Journal of Innovation and Technology Management 2, 313-330.

Hacklin, F., 2008. Management of convergence in innovation - Strategies and capabilities for value creation beyond blurring industry boundaries. Physica, Heidelberg.

Hagedoorn, J., 1993. Understanding the rationale of strategic technology partnering:

Nterorganizational modes of cooperation and sectoral differences. Strategic Management Journal 14 , 371-385.

Hagedoorn, J., Duysters, G., 2002. External sources of innovative capabilities: The preferences for strategic alliances or mergers and acquisitions. Journal of Management Studies 39, 167-188.

Hitt, M.A., Hoskisson, R.E., Johnson, R.A., Moesel, D.D., 1996. The market for corporate control and firm innovation. Academy of Management Journal 39, 1084-1119.

Jeong, D., Cho, K., Park, S., Hong, S., 2016. Effects of knowledge diffusion on international joint research and science convergence: Multiple case studies in the fields of lithium-ion battery, fuel cell and wind power. Technological Forecasting and Social Change 108, 15-27.

Juanola-Feliu, E., Colomer-Farrarons, J., Miribel-Català, P., Samitier, J., Valls-Pasola, J., 2012. Market challenges facing academic research in commercializing nano-enabled implantable devices for in-vivo biomedical analysis. Technovation 32, 193-204.

Karvonen, M., Kässi, T., 2012. Industry convergence analysis with patent citations in changing value systems. International Journal of Business and Systems Research 6, 150-175.

Karvonen, M., Kässi, T., 2013. Patent citations as a tool for analysing the early stages of convergence. Technological Forecasting and Social Change 80, 1094-1107.

Kim, J., Kim, S. and Lee, C., 2018. Anticipating technological convergence: Link prediction using Wikipedia hyperlinks. Technovation, https://doi.org/10.1016/j.technovation.2018.06.008.

Kim, N., Lee, H., Kim, W., Lee, H., Suh, J.H., 2015. Dynamic patterns of industry convergence: Evidence from a large amount of unstructured data. Research Policy 44, 1734-1748.

Kim, W., Lee, J., 2009. Measuring the role of technology-push and demand-pull in the dynamic development of the semiconductor industry: The case of the global DRAM market. Journal of Applied Economics 12, 83-108.

Lee, G.K., 2007. The significance of network resources in the race to enter emerging product markets: The convergence of telephony communications and computer networking, 1989-2001. Strategic Management Journal 28, 17-37.

Lee, H., Lee, S., Yoon, B., 2011. Technology clustering based on evolutionary patterns: The case of information and communications technologies. Technological Forecasting and Social Change 78, 953967. 
Lee, W.S., Han, E.J., Sohn, S.Y., 2015. Predicting the pattern of technology convergence using bigdata technology on large-scale triadic patents. Technological Forecasting and Social Change 100, 317-329.

Lee, H.; Kim, N.; Kwak, K.; Kim, W.; Soh, H.; Park, K., 2016. Diffusion patterns in convergence among high-technology industries: A co-occurrence-based analysis of newspaper article data. Sustainability, $8,1029$.

Lei, D.T., 2000. Industry evolution and competence development: the imperatives of technological convergence. International Journal of Technology Management 19, 699-738.

Linstone, H.A., 2011. Three eras of technology foresight. Technovation 31, 69-76.

Lo, C., Wang, C., Chien, P., Hung, C., 2012. An empirical study of commercialization performance on nanoproducts. Technovation 32, 168-178.

Malhorta, A., Gupta, A.K., 2001. An investigation of firm's strategic response to industry convergence. Academy of Management Proceedings, G1-G6.

Niemann, H., Moehrle, M.G., Walter, L., 2013. The development of business method patenting in the logistics industry - Insights from the case of intelligent sensor networks. International Journal of Technology Management 61, 177-197.

Nyström, A., 2008. Understanding change processes in business networks : A study of convergence in Finnish telecommunications 1985-2005. Abo Akademi University, Turku.

Pennings, J.M., Puranam, P., 2001. Market convergence \& firm strategy: New directions for theory and research. ECIS conference, The future of innovation studies Eindhoven, the Netherlands, September 20-23, 2001.

Porter, M.E., 1985. Competitive Advantage: Creating and sustaining superior performance, New York.

Preschitschek, N., Niemann, H., Leker, J., Moehrle, M.G., 2013. Anticipating industry convergence: semantic analyses vs IPC co-classification analyses of patents. Foresight 15, 446-464.

Robert Bosch $\mathrm{GmbH}, 2013$. Bosch and community wind farm join forces to store energy. http://www.bosch-presse.de/pressportal/de/en/bosch-and-community-wind-farm-join-forces-to-storeenergy-42065.html, accessed 11-08-2017.

Rosenberg, N., 1963. Technological change in the machine tool industry, 1840-1910. The Journal of Economic History 23, 414-443.

Schmidt, J., Makadok, R., Keil, T., 2016. Customer-specific synergies and market convergence. Strategic Management Journal 37, 870-895.

Schnaars, S., Wymbs, C., 2004. On the persistence of lackluster demand - The history of the video telephone. Technological Forecasting and Social Change 71, 197-216.

Spender, J.-C., 1989. Industry recipes: an enquiry into the nature and sources of managerial judgement, Oxford.

The Guardian, 2017. Tesla to build world's biggest lithium ion battery in South Australia. https://www.theguardian.com/australia-news/2017/jul/07/tesla-to-build-worlds-biggest-lithium-ionbattery-in-south-australia, accessed 09-08-2017.

Utterback, J. M., Abernathy, W. J., 1975. A dynamic model of process and product innovation. Omega The International Journal of Management, 3, 6, 639-656. 
Vaseashta, A., 2014. Advanced sciences convergence based methods for surveillance of emerging trends in science, technology, and intelligence. Foresight 16, 17-36.

Venugopalan, S., Rai, V., 2015. Topic based classification and pattern identification in patents.

Technological Forecasting and Social Change 94, 236-250.

Versteeg, T., Baumann, M.J., Weil, M., Moniz, A.B., 2017. Exploring emerging battery technology for grid-connected energy storage with Constructive Technology Assessment. Technological Forecasting and Social Change, 115, 99-110.

vom Stein, N., Sick, N., 2014. Technological distance in academic collaborations: Evidence from battery research. International Journal of Innovation Management 18, 1440011-1-1440011-22.

von Delft, S., Leker, J., 2011. Collaborative innovation in converging industries: The case of electromobility. Proceedings of the 4th ISPIM Innovation Symposium Wellington, New Zealand.

Wagner, F.T., Lakshmanan, B., Mathias, M.F., 2010. Electrochemistry and the future of the automobile. The Journal of Physical Chemistry Letters 1, 2204-2219.

Warth, J., von der Gracht, H.A., Darkow, I., 2013. A dissent-based approach for multi-stakeholder scenario development - The future of electric drive vehicles. Technological Forecasting and Social Change 80, 566-583.

Wernerfeldt, B., 1984. A resource-based view of the firm. Strategic Management Journal, 5, 171-180.

Wirtz, B.W., 2001. Reconfiguration of value chains in converging media and communications markets. Long Range Planning 34, 489-506. 